\title{
Do aggression and impulsivity dominate dark triad across
}

\section{genders?}

\author{
Anupriya Singh $^{1 *}$, Aisha Naeem ${ }^{2}$, Dr. Komal Chandiramani ${ }^{3}$
}

\section{ABSTRACT}

The study investigated gender differences in Overall Dark Triad (Machiavellianism, Narcissism, and Psychopathy), Aggression, Impulsivity, and impact of Dark triad on Aggression and Impulsivity. Data was collected from 214 young adults. Analyses was done using descriptive statistics (mean and standard deviation). T-test was employed to analyze gender differences. Pearson Correlation Method and Multiple regression were used to assess the relation and prediction amongst the variables, respectively. T-test suggested significant gender differences in Machiavellianism, Psychopathy, and Overall Dark Triad, with females scoring high than males. No gender difference was observed in Aggression and Impulsivity. Correlation and regression analyses revealed several significant relationships between the above constructs. The research was concluded by briefly foregrounding some of the study's implications and future directions.

\section{Keywords: Aggression, Dark triad, Gender difference, Impulsivity}

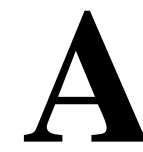

n aversive personality trio of Machiavellianism, Narcissism, and Psychopathy forms the dark triad (Paulhus \& Williams, 2002). Researchers Paulhus and Williams (2002) came up with the 'dark triad' consisting of three personality traits that are overlapping but have different constructs. The traits include Machiavellianism which is linked to hypocrisy and manipulation. The second trait is subclinical narcissism that is associated with dominance, superiority, and egocentric attitude (Paulhus \& Williams, 2002). The last trait subclinical psychopathy is related to higher levels of aggressiveness and impulsivity (Kennealy, Skeem, Walters \& Camp, 2010). So the traits of the dark triad are related to negative aspects of life.

Fehr, Samsom, and Paulhus, (1992) explained the concept of Machiavellianism derived from the writings of the 16th-century Italian author, Niccolò Machiavelli (Machiavelli,14691527). Manipulation and irresponsible behaviour characterize Machiavellianism (Weng, Ran, \& Chui, 2016). According to Làng and Birkas (2015), Machiavellianism relies more

\footnotetext{
${ }^{1}$ Student, Shaheed Rajguru College of Applied Sciences for Women, University of Delhi, Delhi, India ${ }^{2}$ Student, Shaheed Rajguru College of Applied Sciences for Women, University of Delhi, Delhi, India ${ }^{3}$ Assistant Professor, Shaheed Rajguru College of Applied Sciences for Women, University of Delhi, Delhi, India

*Responding Author

Received: July 14, 2020; Revision Received: August 21, 2020; Accepted: August 23, 2020
}

(C) 2020, Singh A, Naeem A \& Chandiramani K; licensee IJIP. This is an Open Access Research distributed under the terms of the Creative Commons Attribution License (www.creativecommons.org/licenses/by/2.0), which permits unrestricted use, distribution, and reproduction in any Medium, provided the original work is properly cited. 
on conditions and less on spontaneity, the correlation of Machiavellianism was less for aggression in females. A study by Lambe, Giachritsis, Garner, and Walker, (2018) suggested that Narcissism refers to characteristics responsible for quarrel, greed, and animosity towards others. Raskin and Hall (1979) developed a subclinical version of narcissism or normal narcissism. Research on the narcissist's self and how it is shaped by the dynamic interaction of cognitive and affective intrapersonal processes and interpersonal selfregulatory strategies that are played out in the social arena (Morf \& Rhodewalt, 2001) further supported the development.

Psychopathy is like Machiavellianism but integrates selfishness with antisocial behaviour and cruelty (Howland, Kosson, Patterson \& Newman, 1993). The traits of psychopathy relate to errant behaviour and are found in children and the youth (Leenarts et al. 2017). The positive correlation between these traits' shares self-centeredness, cold emotions, and aggression (Ali, 2020). Individuals that score high on these factors are most likely to start social distress, indulge in criminal activity, and disturb business peace (Shoemaker, 2018). Glenn and Sellbom in 2015 associated the dark triad with a callous and easily manipulative personality. There is evidence that each of the Dark Triad traits is related to the angry hostility facet of neuroticism (DeShong, Helle, Lengel, Meyer, \& Mullins-Sweatt, 2017).

According to Baron and Richardson (1994) "aggression is any act that harms another individual who is motivated to avoid such harm". Aggression can be shown either directly or indirectly. Any harm that is caused one-on-one by a person (aggressor) towards another person (victim) is identified as a direct form of aggression (Richardson \& Green, 1999). Indirect ways of harming do not include one-on-one, rather, behind a person's (victim) back either physically or verbally (Coyne \& Archer, 2004). There are many studies related to aggression and gender. In one research by Eagely and Steffen (1986) males show higher levels of overt physical aggression than females. However, Archer and Coyne in 2005 reported that women express indirect aggression similarly or more than men. Researchers also indicate that social norms play a vital role in the level of aggression of males and females, for example, Eagerly and Steffeny's 1986 research indicate that most of the cultures 'reward' men for being aggressive and 'punish' women for eliciting the same behaviour. The pattern of aggression for males and females is changing according to modern times (Shaban \& Kumar, 2016). Females experience a prominent level of aggression when compared to males (Shaban \& Kumar, 2016). When males and females are intentionally provoked, they elicit similar levels of verbal aggression (Bettencourt \& Miller, 1996). Women usually get aggressive when they are put under major stress and they lose selfcontrol, contrarily, males tend to get aggressive if their self-esteem is provoked when they attempt to exercise control over others (Campbell \& Muncer, 1987). Forero, Gallardo-Pujol, Maydeu-Olivares, and Andrés-Pueyo, (2009) reported that although there is a relation between aggression and impulsivity, they are separate constructs.

Impulsivity refers to "a predisposition toward rapid, unplanned reactions to internal or external stimuli with diminished regard to the negative consequences of these reactions to the impulsive individual or others" (Potenza, 2007). According to the American Psychiatric Association, 2013, impulsivity may help in identifying some neuropsychiatric conditions like bipolar disorder, addiction, and Attention-Deficit Hyperactivity Disorder. High impulsivity characterizes most neuropsychiatric conditions. Individuals that are high on impulsivity are unable to control themselves and cannot hold up their satisfaction (Monterosso \& Ainslie, 1999). The downfall of impulsivity includes actions that are considered immature, savage, and taken without consideration. These actions result in 
negative outcomes (Evenden, 1999). Gender differences in impulsivity depend on the task and subject samples provided (Weaver \& Wit, 2013). Sex differences in impulsivity are more noticeable during childhood. These differences later depend on maturity level and hormonal changes that affect the brain, cognition, and behaviour of the person (Weinstein \& Dannon, 2015). The Barratt impulsivity scale stipulates factors like intensified motor activity, less attention, and less planning out of which less attention and less planning make up the main factors of impulsivity (Barratt, Monahan \& Steadman, 1994).

The dark triad is remarkably related to direct aggression as well as indirect aggression (Spierings, 2016). One of the dark personality traits i.e. psychopathy is strongly related to aggression (Webster et al., 2016). This study is consistent with another study by Furnham, Richards, and Paulhus, 2013 indicating that individuals that score high on psychopathy are more impulsive and aggressive. Impulsivity is highly associated with narcissism and psychopathy but is not associated with Machiavellianism, hence there seems to be a logical relation of the dark triad with impulsivity (Jones \& Paulhus, 2011). Another study that showed a strong correlation of psychopathy, narcissism, and self-reported impulsivity but no correlation of Machiavellianism with any kind of impulsivity (Malesza \& Kalinowski, 2019) support these findings.

The purpose of the study was to explore the gender differences in Overall Dark Triad (Machiavellianism, narcissism, and Psychopathy), Aggression, Impulsivity, and the impact of Dark triad on Aggression and Impulsivity. The concept of the dark triad was developed in the year 2002 and is new. It had scope for further research especially in the Indian context as most of the existing researches were from the west. The present study is imperative as it is the first research to link the three constructs i.e. dark triad, aggression, and impulsivity with gender differences. The personality traits of an individual influence the behavioural attributes. According to the above-mentioned objective, the following hypothesis was formulated:

1. There would be a significant difference in females and males on the Overall Dark triad and it's dimensions.

2. There would be a significant difference in females and males in Aggression.

3. There would be a significant difference in females and males in Impulsivity.

4. There would be a significant relationship between Dark triad, Aggression, and Impulsivity.

5. Aggression and Impulsivity are significant predictors of the overall dark triad.

\section{METHODOLOGY}

The aim of the present study is to examine the gender differences on the impact that negative traits have on impulsivity and aggression.

\section{Design}

A two-group design based on gender i.e., females and males were used in the present study.

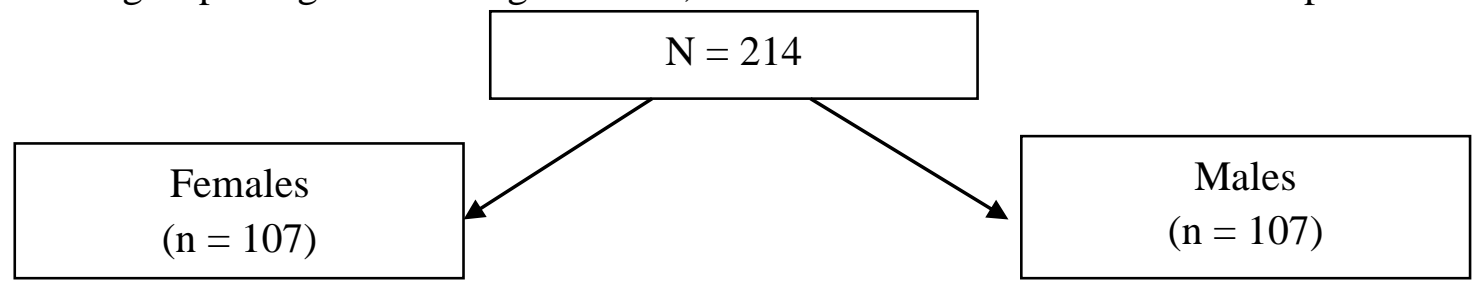

\section{Figure 1: Diagrammatic representation of the study's design}

(c) The International Journal of Indian Psychology, ISSN 2348-5396 (e)| ISSN: 2349-3429 (p) | 515 


\section{Sample}

The population of study comprised of young adults, in the age group of 18-22 years old, residing in Delhi, NCR region. Purposive sampling was used and a total sample of 214, with 107 females and 107 males, was used for the purpose of this study.

Table 1: Demographic details of the participants $(N=214)$

\begin{tabular}{|l|l|l|l|l|l|l|}
\hline Gender & Ages & $\mathbf{1 8}$ years & $\mathbf{1 9}$ years & $\mathbf{2 0}$ years & $\mathbf{2 1}$ years & 22 years \\
\hline \multirow{3}{*}{ Females } & Age (in years) & 10 & 39 & 44 & 11 & 3 \\
\cline { 2 - 7 } & $\begin{array}{l}\text { Age (in } \\
\text { percentage }\end{array}$ & $9.35 \%$ & $36.45 \%$ & $41.12 \%$ & $10.28 \%$ & $2.80 \%$ \\
\hline \multirow{2}{*}{ Males } & Age (in years) & 10 & 32 & 49 & 10 & 6 \\
\cline { 2 - 7 } & $\begin{array}{l}\text { Age (in } \\
\text { percentage }\end{array}$ & $9.35 \%$ & $29.90 \%$ & $45.79 \%$ & $9.35 \%$ & $5.61 \%$ \\
\hline
\end{tabular}

Table 1 depicts the demographic details of the sample. The average age in females and males was 20. In both females and males, maximum participants belonged to the age of 20 years and least to the age of 22 years.

\section{Instruments}

1. Short Dark Triad (SD3): Three overlapping aversive personality traits namely, Machiavellianism, Psychopathy, and Narcissism constitute the dark triad. The SD3 (Jones and Paulhus, 2014) is a simple 27 item instrument, which measures the three traits individually. It is a self-report questionnaire and some items have a reverse scoring. It uses a Likert scale type of responding system, from 1 (strongly agree) to 5 (strongly disagree). The psychometric properties of SD3 indicate that it has an acceptable internal consistency for every dimension. Jones and Paulhus (2014) concluded that the scales subscales offer close proximate for all the Dark Triad traits they were supposed to measure. Malesza, Ostaszewski, Büchner, and Kaczmarek (2019) found SD3 to have high test-retest reliability.

2. Novaco Anger Inventory (NAI): It is a shorter version of the original NAI- longform, and has 25 questions. NAI-25 (Novaco, 1975) has questions that describe situations that may lead to anger. Responses are marked on a Likert scale, ranging from 0 (very little) to 4 (very much). It has a test-retest reliability of between 0.78 0.91 (Mills, Kroner \& Forth, 1998).

3. Barratt Impulsiveness Scale (BIS): It is a scale used to measure behavioral and personality aspects of impulsivity. The B.I.S (Barratt, E.S., 1994) is a widely used 30 item instruments, with a four-point Likert type of scale for responding, from 1 (Rarely/Never) to 4 (Almost Always/Always). BIS has a positive significant correlation with the Aisne Impulsivity questionnaire, this suggests criterion validity. Lilian and Andrea (2013) found the scale to be reliable after analyzing internal consistency and homogeneity of the items.

\section{Procedure}

The objective of the current study was to explore the gender differences in Overall Dark triad, Aggression, Impulsivity, and the impact of Aggression and Impulsivity on the Overall Dark triad. A total sample of 214, with 107 females and 107 males was used in the present study. Convenience sampling was used and the responses were collected via a Google Form. Due consent was obtained, and the participants were briefed that their responses would remain anonymous and confidential, and participation was voluntary and could be 
terminated at any given time. All necessary instructions for the completion of questionnaires' were provided. The study administered a total of three tests namely, Short Dark Triad (Jones \& Paulhus, 2014), Novaco Anger Inventory (Novaco, 1975), and Barratt Impulsiveness Scale (Barratt, E.S., 1994). All participants took approximately 15-20 minutes to complete all the questions.

\section{RESULTS}

The study analyzed the data using descriptive and inferential statistics via the Statistical Package for Social Sciences (SPSS 19.0). It used bar diagrams to represent Descriptive information. It calculated mean and standard deviations (Table 1) from the raw scores and represented in a tabular form. The study used Levene's Test of Equality of Variances to test the assumption of homogeneity of variances (Table 2) and Shapiro-Wilk Tests of Normality (Table 3) to assess the normalcy of scores. It administered T-test Independent to find out the significant mean differences between the two groups.
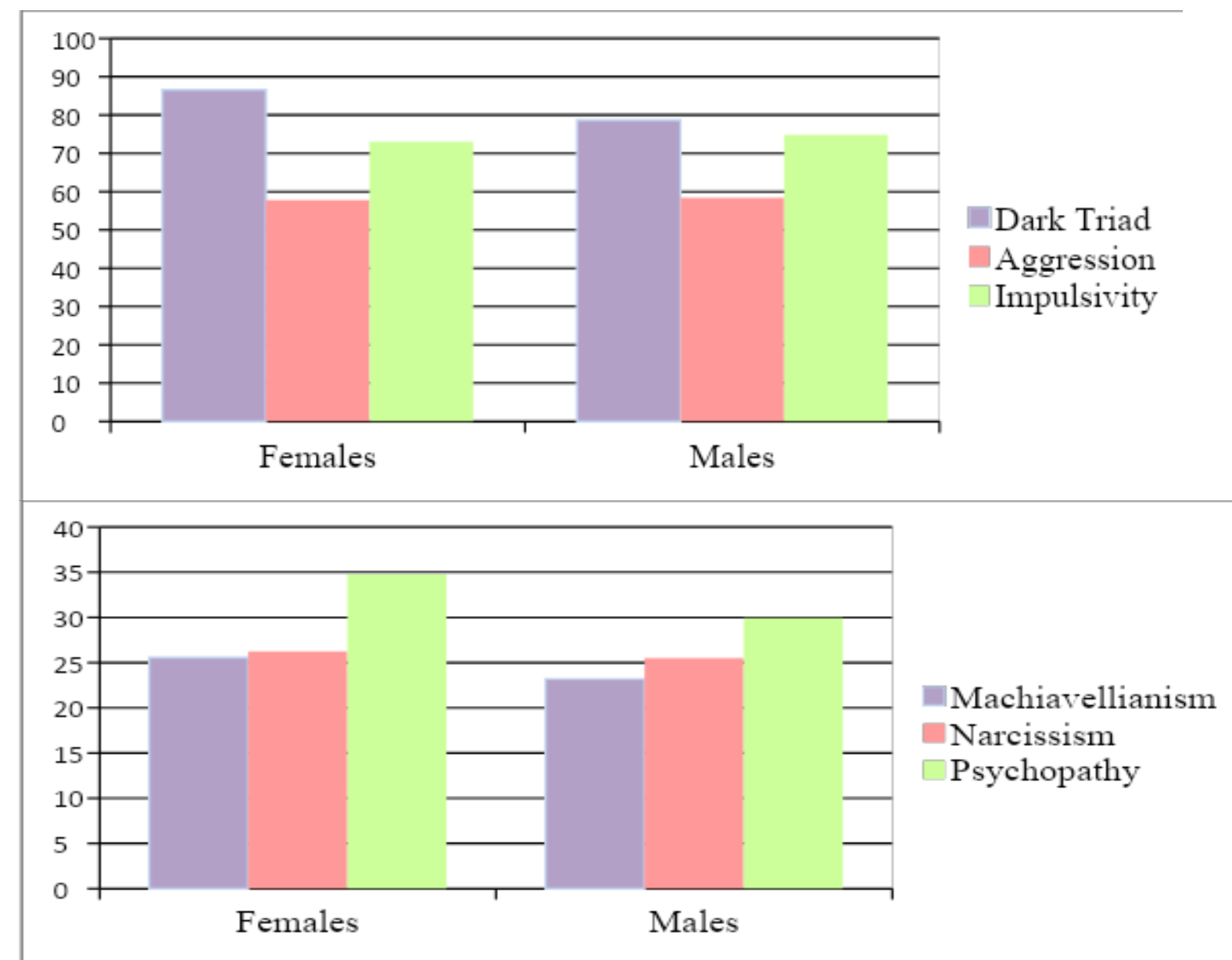

Graph 1: A graphical representation of the Mean scores of Females and Males across Overall Dark Triad, Aggression, and Impulsivity scales; And Mean scores of Females and Males Machiavellianism, Narcissism, and Psychopathy scales.

Graph 1 shows females were high on Overall Dark triad and males were high on Aggression and Impulsivity and females were also high on Machiavellianism, narcissism, and psychopathy. 
Table 2: Levene's Test of Equality of Variances on Dark Triad (and its sub-scales), Aggression and Impulsivity scales $(N=214)$

\begin{tabular}{|l|l|l|}
\hline Variables & $\boldsymbol{F}$ & Sig. \\
\hline Machiavellianism & 1.049 & 0.307 \\
\hline Narcissism & 0.186 & 0.667 \\
\hline Psychopathy & 1.038 & 0.309 \\
\hline Overall Dark Triad & 1.955 & 0.164 \\
\hline Aggression & 0.151 & 0.698 \\
\hline Impulsivity & 1.374 & 0.242 \\
\hline
\end{tabular}

Table 2 represents the Levene's Test of Equality of Variance, which provides an F-statistic (Levene Statistic) and significance value (p-value). Since all the variables had a value significantly greater than 0.05 (i.e., $\mathrm{p} \geq .05$ ), the study treated Equality of variances among the groups as equal and did not find the assumption of homogeneity of variance to be violated. Owing to this, the study used parametric statistics.

Table 3: Shapiro-Wilk test of Normality of Dark Triad (and its sub-scales), Aggression and Impulsivity scales by Females and Males $(d f=107)$

\begin{tabular}{|l|l|l|l|}
\hline Variables & Gender & Statistic & Sig. \\
\hline \multirow{2}{*}{ Machiavellianism } & Females & 0.988 & 0.449 \\
\cline { 2 - 4 } & Males & 0.981 & 0.135 \\
\hline \multirow{2}{*}{ Narcissism } & Females & 0.988 & 0.435 \\
\cline { 2 - 4 } & Males & 0.984 & 0.216 \\
\hline \multirow{2}{*}{ Overall Dark Triad } & Females & 0.988 & 0.424 \\
\cline { 2 - 4 } & Males & 0.982 & 0.162 \\
\hline \multirow{2}{*}{ Aggression } & Females & 0.992 & 0.814 \\
\cline { 2 - 4 } & Males & 0.994 & 0.936 \\
\hline \multirow{2}{*}{ Impulsivity } & Females & 0.991 & 0.662 \\
\cline { 2 - 4 } & Males & 0.989 & 0.122 \\
\hline & Females & 0.981 & 0.293 \\
\cline { 2 - 4 } & Males & 0.985 & \\
\hline
\end{tabular}

Table 3 represents the Shapiro-Wilk Test for assessing normality. For Females and Males, the significant values of the Shapiro-Wilk Test were greater than $0.05(\mathrm{p} \geq .05)$ indicating that the data were normally distributed and parametric statistics could be used.

Table 4: Results of mean, standard deviation, $t$-value and $p$ value on the measures of Machiavellianism, narcissism, psychopathy, overall dark triad, aggression and impulsivity. In females and males $(d f=212)$

\begin{tabular}{|l|l|l|l|l|}
\hline Variables & $\begin{array}{l}\text { Females } \\
(\mathbf{n = 1 0 7}) \\
\text { Mean } \pm \text { SD }\end{array}$ & $\begin{array}{l}\text { Males } \\
(\mathbf{n = 1 0 7}) \\
\text { Mean } \pm \text { SD }\end{array}$ & $\boldsymbol{t}$-value & $\begin{array}{l}\boldsymbol{p} \text {-value } \\
\text { Sig.(2- } \\
\text { tailed) }\end{array}$ \\
\hline Machiavellianism & $25.58 \pm 4.59$ & $23.21 \pm 4.95$ & 3.63 & 0.00 \\
\hline Narcissism & $26.25 \pm 4.66$ & $25.50 \pm 4.77$ & 1.15 & 0.24 \\
\hline Psychopathy & $34.77 \pm 4.80$ & $29.96 \pm 5.54$ & 6.78 & 0.00 \\
\hline Overall Dark Triad & $86.61 \pm 9.15$ & $78.68 \pm 10.76$ & 5.80 & 0.00 \\
\hline Aggression & $57.73 \pm 13.66$ & $58.35 \pm 14.04$ & -0.32 & 0.74 \\
\hline Impulsivity & $73.06 \pm 7.33$ & $74.84 \pm 8.08$ & -1.68 & 0.09 \\
\hline
\end{tabular}


Table 4 depicts the results of The Overall Dark Triad (and its sub-scales of Machiavellianism, Narcissism, and Psychopathy), Aggression, and Impulsivity. The study observed that there was a statistically significant difference in the t-values for the dimensions of Machiavellianism, Psychopathy, and Overall Dark triad. This indicated a statistically significant difference between the two groups of females and males. However, Impulsivity and Aggression did not have a statistically significant difference between females and males.

Table 5: Correlation between Overall Dark Triad with Aggression and Impulsivity for the overall sample.

\begin{tabular}{|l|l|l|l|}
\hline & Dark Triad & Aggression & Impulsivity \\
\hline Overall Dark Triad & 1 & $-.284^{* *}$ & $-.246^{* *}$ \\
\hline Aggression & $-.284^{* *}$ & 1 & $.211^{* *}$ \\
\hline Impulsivity & $-.246^{* *}$ & $.211^{* *}$ & 1 \\
\hline
\end{tabular}

**: Correlation is significant at the 0.01 level (2-tailed).

The study used the Pearson Product Moment Method of Correlation to identify the relationship between Overall Dark triad, Aggression, and Impulsivity scores for the overall sample. Results depicted in Table 5 suggest that there was a significant but low correlation amongst all the variables. Dark triad had a low negative correlation with aggression and impulsivity.

Table 6: Multiple Regression Analysis of Aggression and Impulsivity with Overall Dark Triad.

\begin{tabular}{|c|c|c|c|c|c|c|c|}
\hline Predictors & $\mathbf{R}$ & $\mathbf{R}^{2}$ & Adjusted $\mathbf{R}^{2}$ & $\mathbf{F}$ & B & $d f$ & $t$ \\
\hline Aggression & \multirow[t]{2}{*}{$0.34^{\mathrm{a}}$} & \multirow[t]{2}{*}{0.12} & \multirow[t]{2}{*}{0.11} & \multirow[t]{2}{*}{13.93} & -0.19 & \multirow[t]{2}{*}{$(2,211)$} & -3.67 \\
\hline Impulsivity & & & & & -0.27 & & -2.94 \\
\hline
\end{tabular}

Predictors: (Constant), Impulsivity, Aggression.

The study conducted a multiple regression analysis to examine the proportion of variance in the criterion variable (Dark Triad) that was predicted by the predictor variables (Aggression and Impulsivity). Table 6 represents the results, which suggests that $\mathrm{R}^{2}$ was equal to 0.11 , indicating that $11 \%$ of the total variability in the Dark Triad was accounted for by Aggression and Impulsivity $\left(\mathrm{R}^{2}=0.11 ; \mathrm{F}=13.93 ; \mathrm{p}<0.05\right)$.

\section{DISCUSSION}

The objective of the current study was to explore the gender differences in Overall Dark triad, Aggression, Impulsivity, and the impact of Aggression and Impulsivity on the Overall Dark triad. The construct of Dark triad was relatively new and had scope for further research specifically in the Indian context as the majority of the researches were from the west. The present study was a first attempt to examine the interplay of dark triad, aggression, and impulsivity concerning gender differences.

The Dark Triad consists of three personality characteristics that are Narcissism, Machiavellianism, and Psychopathy (Paulhus \& Williams, 2002). The everyday term aggression can be explained as an act that causes physical or emotional harm through verbal or physical exploitation. Impulsivity can be explained as hasty decisions taken by a person due to behavioural or emotional lack of self-control that may or may not have regretful 
consequences. The study used purposive sampling to collect and descriptive and inferential statistics to analyze the data.

The study found significant group differences in Females and Males on Overall Dark Triad and its dimensions, Machiavellianism, Narcissism, and Psychopathy, indicating that females had a higher mean score as compared to males. Thus, it accepted hypothesis 1 . Women have faced oppression for centuries, and have learned to be manipulative and deceptive to get their way. A similar difference in narcissism could be accounted for, as girls grow up they consume pop media, where "ideal" women are presented as having narcissist qualities (example: Mean girls) for instance, excessive self-love, need for constant admiration, belittling others, etc. Psychopathy's scores indicate gender differences in females and males, by females scoring high. The labelling theory (Becker, 1963) which states that self- identity and behaviour of an individual can be influenced by the words or labels used to describe them. Since women are referred to as "psychopaths" on certain occasions, this could explain the reinforcement of the tag and thus females tend to act upon it. Schmitt et al (2016) found gender differences in the dark triad scores of females and males, where males scored higher on the dimensions. There have been researches where differences in gender have been found in dark triad traits (Grijalva et al, 2014; Jonason, Li, Webster, \& Schmitt, 2009).

Hypothesis 2 stated that there would be a significant difference in Females and Males in Aggression was rejected; both females and males had a similar score. In the 21st century, social conditioning has been such, where aggressive acts irrespective of the gender of the perpetrator have little tolerance. Shaban and Kumar (2016) found related results of equal aggression in young males and females in India. When males and females are provoked intentionally, they elicit similar levels of verbal aggression (Bettencourt and Miller, 1996).

The study found no significant difference in females and males in impulsivity, thus rejecting hypothesis 3 which stated that there would be a significant gender difference in impulsivity. Since women and men are being brought up in similar environments now, both the genders are equally reprimanded or praised for the consequence of an impulsive act. Thus, the study did not observe significant discrepancies between females and males scores. Solanki and Bhatnagar (2008) did a study on impulsivity in the Indian context and found that no gender difference exists between females and males on the measure of impulsivity.

The study establishes a significant low positive correlation between Aggression and Impulsivity, while it established a significant but low negative correlation between Dark Triad, Aggression and impulsivity. Hypothesis 4 states that there would be a significant relationship between Dark triad, Aggression, and Impulsivity was rejected. With growing awareness and availability of interventions, negative behavioural traits such as aggression and impulsivity have been managed. And since childhood most children are discouraged from behaving negatively, these conditions allow individuals to have better control over their behavioural tendencies. The study's finding was inconsistent with Jones and Paulhus's (2011) findings that indicated that dark triad traits have a relation with impulsivity and Malesza and Ostaszewski's (2016) findings which suggest a relation between psychopathy, narcissism and impulsivity does exist, although Machiavellianism is not associated with impulsivity. Fanti and Kimonis (2012) found narcissism, psychopathy, and aggression to have a relationship.

Aggression and Impulsivity were found to be significant predictors of the Overall Dark triad. The direction of prediction was negative. Indicating that as one unit of Overall Dark triad

(c) The International Journal of Indian Psychology, ISSN 2348-5396 (e)| ISSN: 2349-3429 (p) | 520 
increased, one unit of Aggression and Impulsivity decreased. Hypothesis 5 stated that Aggression and Impulsivity were significant predictors of the Overall Dark triad, was accepted. Aggression and Impulsivity accounted for a low significant amount of negative variance in the Overall Dark triad. The study was conducted on young adults, residing in the Indian subcontinent, where familial relationships are highly valued. The sample was young and had an impressionable mind. Since, most interaction existed within the core groups consisting of Family, Teachers/ Colleagues, and friends; these groups play a potential role in shaping the behaviour of individuals, thus influencing their personality. Humans interact with the environment, as a result, behaviour changes from one situation to another, which indicates that personality is a stable yet dynamic trait. Thus, the variation in scores could be accounted for by individual differences.

The present study has certain limitations. First being, purposive sampling was used, which made the data not the purest for generalization. Age range was 18-22 years, thus limiting the scope of research. The questionnaires used in the study were not adapted to the Indian context. Responses were collected online and from self-report questionnaires, which could cause errors in the data collected.

The study has future implications being, variables other than aggression and impulsivity can be used to study different relationships the dark triad has with other constructs. A different methodological approach can be used to acquire data. Other demographic details like education qualifications, relationship status, etc., can be used to enhance the scope of the paper. And lastly, a larger geographical area can be covered and a larger sample can be collected for more accuracy.

\section{CONCLUSION}

The present study makes some important contributions to the theoretical framework of the Dark triad, particularly in the Indian context. The study finds that females are higher in dark triad traits as compared to males, although females and males scored similarly on aggression and impulsivity. Additionally, no relation is established between dark triad, aggression, and impulsivity. Thus, the study provides an insight into the influence of Aggression and Impulsivity on the Dark triad.

\section{REFERENCES}

Ahmad Sa'ad AL sheikh Ali (2020). Delinquency as predicted by dark triad factors and demographic variables. International Journal of Adolescence and Youth, 25(1), 661675.

Archer, J., \& Coyne, S. M. (2005). An Integrated Review of Indirect, Relational, and Social Aggression. Personality and Social Psychology Review, 9(3), 212-230.

Baron, R. A., \& Richardson, D. R. (2004). Human Aggression. New York: Plenum Pub.

Barratt, E. S., Monahan, J., \& Steadman, H. J. (1994). Impulsiveness and aggression. Violence and mental disorder. Developments in risk assessment, 10, 61-79.

Becker, H. S. (1963). Outsiders: Studies in the sociology of deviance. New York: Free Press.

Bettencourt, B. A., \& Miller, N. (1996). Gender differences in aggression as a function of provocation: a meta-analysis. Psychological bulletin, 119(3), 422-447.

Buss, A. H., \& Perry, M. (1992). The Aggression Questionnaire. Journal of Personality and Social Psychology, 63(3), 452-459.

Campbell, A., \& Muncer, S. (1987). Models of anger and aggression in the social talk of women and men. Journal for the Theory of Social Behaviour, 17(4), 489-511. 
Coyne, S.M. \& Archer, J. (2004) Indirect Aggression in the Media: A Content Analysis of British Television Programs. Aggressive Behavior, 30, 254-271.

Crysel, L. C., Crosier, B. S., \& Webster, G. D. (2013). The Dark Triad and risk behavior. Personality and Individual Differences, 54(1), 35-40.

DeShong, H. L., Helle, A. C., Lengel, G. J., Meyer, N., \& Mullins-Sweatt, S. N. (2017). Facets of the dark triad: Utilizing the five-factor model to describe Machiavellianism. Personality and Individual Differences, 105, 218-223.

Diagnostic and statistical manual of mental disorders: DSM-5. (2013). Arlington, VA: American Psychiatric Association.

Eagly, A. H., \& Steffen, V. J. (1986). Gender and aggressive behavior: A meta-analytic review of the social psychological literature. Psychological Bulletin, 100(3), 309330.

Eagly, A. H., \& Steffen, V. J. (1986). Gender stereotypes, occupational roles, and beliefs about part-time employees. Psychology of Women Quarterly, 10(3), 252-262.

Evenden, J. L. (1999). Varieties of impulsivity. Psychopharmacology, 146(4), 348-361.

Fanti, K. A., \&Kimonis, E. R. (2012). Bullying and Victimization: The Role of Conduct Problems and Psychopathic Traits. Journal of Research on Adolescence, 22(4), 617631.

Furnham, A., Richards, S. C., Paulhus, D. L. (2013) The Dark Triad of personality: A 10 year review. Social and Personality Psychology Compass, 7(3): 199-216.

García-Forero, C., Gallardo-Pujol, D., Maydeu-Olivares, A., \& Andrés-Pueyo, A. (2009). Disentangling impulsiveness, aggressiveness and impulsive aggression: an empirical approach using self-report measures. Psychiatry research, 168(1), 40-49.

Glenn, A. L., \&Sellbom, M. (2015). Theoretical and empirical concerns regarding the dark triad as a construct. Journal of Personality Disorders, 29, 360-377.

Grijalva, E., Newman, D. A., Tay, L., Donnellan, M. B., Harms, P. D., Robins, R. W., \& Yan, T. (2014). Gender differences in narcissism: A meta-analytic review. Psychological Bulletin. Advance online publication. DOI:10.1037/a0038231

Hornsveld, Ruud \& Muris, Peter \& Kraaimaat, Floris. (2011). The Novaco Anger ScaleProvocation Inventory (1994 Version) in Dutch Forensic Psychiatric Patients. Psychological assessment, 23. 937-944.

Howland, E. W., Kosson, D. S., Patterson, C. M., \& Newman, J. P. (1993). Altering a dominant response: Performance of psychopaths and low-socialization college students on a cued reaction time task. Journal of Abnormal Psychology, 102(3), 379387

Jonason, P. K., Li, N. P., Webster, G. D., \& Schmitt, D. P. (2009). The dark triad: Facilitating a short-term mating strategy in men. European Journal of Personality: Published for the European Association of Personality Psychology, 23(1), 5-18.

Jones, D. N., \& Paulhus, D. L. (2011). The role of impulsivity in the Dark Triad of personality. Personality and Individual Differences, 51(5), 679-682.

Jones, D. N., \& Paulhus, D. L. (2014). Introducing the short dark triad (SD3) a brief measure of dark personality traits. Assessment, 21(1), 28-41.

Jones, D. N., \& Neria, A. L. (2015). The Dark Triad and dispositional aggression. Personality and Individual Differences, 86, 360-364.

Kennealy, P. J., Skeem, J. L., Walters, G. D., \& Camp, J. (2010). Do core interpersonal and affective traits of PCL-R psychopathy interact with antisocial behavior and disinhibition to predict violence?. Psychological assessment, 22(3), 569.

Lambe, S., Hamilton-Giachritsis, C., Garner, E., \& Walker, J. (2018). The role of narcissism in aggression and violence: A systematic review. Trauma, Violence, \& Abuse, 19(2), 209-230. 
Láng, A., \& Birkás, B. (2015). Machiavellianism and parental attachment in adolescence: Effect of the relationship with same-sex parents. Sage Open, 5, 1-7.

Leenarts, L. \& Dölitzsch, C. \& Pérez, Tania \& Schmeck, Klaus \& Fegert, Joerg \& Schmid, Marc. (2017). The relationships between gender, psychopathic traits, and selfreported delinquency: A comparison between a general population sample and a high-risk sample for juvenile delinquency. Child and Adolescent Psychiatry and Mental Health. DOI 10.1186/s13034-017-0202-3.

Lilian, S.G. \& Andrea, C.S. (2013). Reliability and validity of Barratt impulsiveness scale (BIS-11) in adolescents. Revista Chilena de Neuro-Psiquiatria, 51,245-254.

Malesza, M., \&Ostaszewski, P. (2016). Dark side of impulsivity-Associations between the Dark Triad, self-report and behavioral measures of impulsivity. Personality and Individual Differences, 88, 197-201.

Malesza, M., Ostaszewski, P., Büchner, S. \& Kaczmarek (2019). The Adaptation of the Short Dark Triad Personality Measure - Psychometric Properties of a German Sample. CurrPsychol 38, 855-864.

Mills, J. F., Kroner, D. G., \& Forth, A. E. (1998). Novaco Anger Scale: Reliability and validity within an adult criminal sample. Assessment, 5(3), 237-248.

Monterosso, J., \& Ainslie, G. (1999). Beyond discounting: possible experimental models of impulse control. Psychopharmacology, 146(4), 339-347.

Morf, C. C., \& Rhodewalt, F. (2001). Unraveling the paradoxes of narcissism: A dynamic self-regulatory processing model. Psychological inquiry, 12(4), 177-196.

Novaco, R. W. (1975). Anger control: The development and evaluation of an experimental treatment. Lexington.

Paulhus, D. L., \& Williams, K. M. (2002). The dark triad of personality: Narcissism, Machiavellianism, and psychopathy. Journal of research in personality, 36(6), 556563.

Potenza M. N. (2007). To do or not to do? The complexities of addiction, motivation, selfcontrol, and impulsivity. The American journal of psychiatry, 164(1), 4-6.

Raskin, R. N., \& Hall, C. S. (1979). A narcissistic personality inventory. Psychological reports, 45(2), 590.

Richardson, D. S., \& Green, L. R. (2003). Defining direct and indirect aggression: The Richardson Conflict Response Questionnaire. Revue Internationale de Psychologie Sociale, 16(3), 11-30.

Schmitt, D. P., Long, A. E., McPhearson, A., O'Brien, K., Remmert, B., \& Shah, S. H. (2017). Personality and gender differences in global perspective. International Journal of Psychology, 52, 45-56.

Shaban, N., \& Kumar, P. (2016). Young adults and aggression: a comparative study of gender differences. The International Journal of Indian Psychology, 3(4), 106-114.

Shoemaker, D. J. (2018). Theories of delinquency: An examination of explanations of delinquent behavior. Oxford University Press.

Singh, P., Solanki, R. K., \& Bhatnagar, P. S. (2008). BIS-11A-Hindi version: A preliminary study of impulsivity in rural and urban Indian adolescents. Indian Journal of Psychiatry, 50(2), 96.

Spielberger, C. D., \& Butcher, J. N. (1992). Advances in personality assessment. Hillsdale, NJ: L. Erlbaum Associates.

Spierings, S. (2014). Relationship between the Dark Triad and aggression. Tilburg school of Social and Behavioral Sciences. Developmental Psychology Warandelaan 2, 5037 AB Tilburg, the Netherlands. Student ANR: s119087

Weafer, J., \& de Wit, H. (2014). Sex differences in impulsive action and impulsive choice. Addictive behaviors, 39(11), 1573-1579.

(c) The International Journal of Indian Psychology, ISSN 2348-5396 (e)| ISSN: 2349-3429 (p) | 523 
Webster, G. D., Gesselman, A. N., Crysel, L. C., Brunell, A. B., Jonason, P. K., Hadden, B. W., \& Smith, C. V. (2016). An actor-partner interdependence model of the Dark Triad and aggression in couples: Relationship duration moderates the link between psychopathy and argumentativeness. Personality and Individual Differences, 101, 196-207.

Weinstein, A., \& Dannon, P. (2015). Is impulsivity a male trait rather than female trait? Exploring the sex difference in impulsivity. Current behavioral neuroscience reports, 2(1), 9-14.

Weng, X., Ran, M. S., \& Chui, W. H. (2016). Juvenile delinquency in Chinese adolescents: An ecological review of the literature. Aggression and violent behavior, 31, 26-36.

Whiteside, S. P., \& Lynam, D. R. (2001). The five-factor model and impulsivity: Using a structural model of personality to understand impulsivity. Personality and individual differences, 30(4), 669-689.

\section{Acknowledgements}

The authors would like to thank Dr. Komal Chandiramani for her constant guidance and their family and friends for support. The authors would also like to thank the participants for their involvement in the study.

\section{Conflict of Interest}

The authors declared this paper to bear no conflict of interest.

How to cite this article: Singh A, Naeem A \& Chandiramani K (2020). Do aggression and impulsivity dominate dark triad across genders? International Journal of Indian Psychology, 8(3), 513-524. DIP:18.01.061/20200803, DOI:10.25215/0803.061 